\title{
A CONSTRUÇ̃̃O DO CASO CLÍNICO COMO FORMA DE PESQUISA EM PSICANÁLISE
}

Alexandre Costa Val e Mônica Assunção Costa Lima

\author{
Alexandre Costa Val \\ Membro do Núcleo \\ de Investigação \\ em Anorexia e \\ Bulimia/HC-UFMG, \\ com mestrado em \\ Ciências da Saúde, \\ Faculdade de \\ Medicina da UFMG. \\ Mônica Assunção \\ Costa Lima \\ Membro do Núcleo \\ de Investigação \\ em Anorexia e \\ Bulimia/HC- \\ UFMG; professora \\ do Departamento \\ de Psicologia \\ da PUC-MG; \\ doutora em Teoria \\ Psicanalítica/UFRJ.
}

RESUMO: O artigo fundamenta a noção de construção do caso em psicanálise como meio de pesquisa e de trabalho em equipe interdisciplinar, tomando como referência as contribuições de Freud, em 1937, e as do psiquiatra italiano Carlo Viganò. Propõe uma aproximação do inanalisável e da verdade histórica freudianos com o Real que se depura de um caso clínico por meio de sua construção. Formaliza os momentos essenciais no processo da construção do caso como metodologia de trabalho, evidenciando a possibilidade de transmissão ao final do processo.

Palavras-chave: Construção do caso, metodologia, transmissão.

ABSTRACT: The clinical case construction as a way of Research in Psychoanalysis. The article substantiates the notion of case construction in psychoanalysis as a way of research and interdisciplinary teamwork, with reference of Freud's contributions in 1937 and Italian psychiatrist Carlo Viganò. It is proposed an approach of unanalyzable and historical Freudian truth with Real which is debugging of a case through its construction. It also formalizes those essential moments in the process of case construction as a methodology of working, showing the possibility of transmission in the end of process.

Keywords: Case construction, methodology, transmission. 
“A psicanálise constitui uma combinação notável, pois abrange não apenas um método de pesquisa das neuroses, mas também um método de tratamento baseado na etiologia assim descoberta."

(Freud, 1913 [1911]/1996, p.225)

\section{APRESENTAÇÃO DA QUESTÃO}

No campo psicanalítico, a investigação clínica sempre esteve intimamente associada à terapêutica e à teorização sobre o psíquico (FREUD, 1923 [1922]/1996). Freud demonstra isso através do estudo minucioso de casos que se tornaram paradigmáticos e influenciaram de forma decisiva a produção de seu arcabouço teórico.

O método de pesquisa propriamente psicanalítico sempre foi objeto de questionamento por não se adequar ao modelo da ciência e, na atualidade, trava um debate especial com a "Medicina Baseada em Evidências”, tão em voga. Fundamentar um método clínico que valorize a transferência e a abordagem das singularidades do caso se justifica pelas contribuições lapidares que ele pode trazer para a condução de casos graves no campo da Saúde Mental, sendo este o objetivo do presente artigo.

Para desenvolver tal fundamentação, tomaremos como referência a noção de construção do caso proposta pelo psiquiatra e psicanalista italiano Carlo Viganò, que se baseia na elaboração dinâmica de um saber cujo foco é o sujeito que sofre de seu sintoma e introduz uma perspectiva diferente da formalização empírica idealizada pela ciência positivista que exclui o sujeito em favor da objetividade e da universalidade (VIGANÒ, 1999).

Antes, no entanto, de expor e desdobrar a noção de construção de caso clínico em Viganó, convém situá-la de modo mais preciso. Quando falamos de construção do caso, fazemos oposição a outras práticas de elaboração clínica baseadas em protocolos semiológicos. Trata-se de forma de acompanhamento do paciente baseada no discurso e no diagnóstico estrutural, com o objetivo de estabelecer balizas para a condução do tratamento.

Seria prudente questionarmos se a oposição da psicanálise à “Medicina baseada em Evidências" e às Neurociências asseguraria a demonstração de um método especificamente psicanalítico. Não estamos certos de poder responder afirmativamente a essa pergunta. Freud, no artigo Sobre o início do tratamento (1913) é avesso à proposição de algo que possa ser chamado de método psicanalítico. Neste texto, o fundador da psicanálise prefere chamar suas indicações para o tratamento de "recomendações", nomeando de "regra" apenas a associação livre. Compara o processo analítico ao jogo de xadrez, no qual apenas a primeira e a última jogadas estão definidas. Entre as duas encontramos as mais amplas variações, o que contraria toda perspectiva de um padrão a seguir (FREUD, 
1913/1996). Além disso, não podemos considerar estabelecida uma metodologia de construção do caso em psicanálise nem mesmo em Viganò. Este autor, assim como outros, tem feito esforços consideráveis para definir diretrizes neste campo e este artigo tem a intenção de participar desta tarefa que, no entanto, devemos reconhecer, permanece inacabada.

Feitas as ressalvas acima, é importante dizer que acreditamos, contudo, na existência de condições propriamente analíticas de referir-se a sua clínica, marcadas por certas características: 1) o ponto de partida é sempre o caso; 2) o sujeito está no centro de seu tratamento, o que o torna, como sugere Figueiredo (2004), o protagonista na construção de uma verdade válida para ele, e não, necessariamente, para o universal; 3) por último, trata-se de uma experiência orientada em direção ao Real.

Viganò convida a pensar a construção do caso como uma orientação da experiência em direção ao Real. O autor retoma a etimologia da palavra "caso" para reforçar essa ideia. Mostra que caso vem do termo latino, cadere, que significa cair ou ir para fora de uma regulação simbólica. Propõe que construir um caso é ir ao encontro do Real, com aquilo que não se pode dizer, e que pode ser circunscrito por um saber a partir de uma operação metafórica (VIGANÒ, 1999).

A definição de Viganò da construção do caso como uma operação capaz de extrair o Real que escapa à regulação simbólica está afinada ao conceito lacaniano de Real tal como ele é apresentado no Seminário XX. Ali, o Real aparece como ponto de impasse da escrita. A escrita sustenta o que não se pode escrever. Em certo momento do seminário, Lacan usa a lógica modal aristotélica para conjugar os modos de cada sujeito se relacionar com a função fálica. Ele modifica a contribuição de Aristóteles para dela melhor se servir e transpõe as proposições modais para o registro da escrita. Define o necessário como aquilo que não cessa de se escrever, o que se escreve sem parar. A contingência é apontada como o que cessa de não se escrever, como o que pode eventualmente se escrever ou como o que pode se escrever de um modo ou de outro. O possível é o que cessa de se escrever, o que não está escrito de uma vez por todas. E, por fim, apresenta o impossível como o que não cessa de não se escrever, o que não se escreve jamais, concluindo que este impossível é o Real (LACAN, 1972-73/1975, p.85-87).

Ainda neste seminário, Lacan recorre à lógica para elaborar sua teoria sobre a sexuação, processo em função do qual o gozo do sujeito, ao passar pelo significante, torna-se fálico. O recurso à lógica se explica pelo fato de que, para o autor, o real do sexo é o impossível de se escrever da relação sexual. Como ele supõe que as lógicas existentes alcançam uma formalização do impossível, acredita que, por meio delas, abre-se a possibilidade de cernir o impossível do sexo (LACAN, 1972-73/1975, p.69). 
Ao que parece, para Viganò, este é o objetivo da construção do caso: sua redução a uma escrita mínima, que permitiria a circunscrição do Real como impossível. Isso é o que buscaremos explicitar ao longo da argumentação, partindo de uma contribuição importante sobre o assunto: o conceito freudiano de construção. Examinemos, pois, com cuidado, o que vem a ser construir um caso em psicanálise, partindo do termo construção, introduzido por Freud no texto Construções em análise (1937), e das contribuições dos textos que lhe são contemporâneos: Análise terminável e interminável (1937) e Moisés e 0 monoteísmo (1937).

\section{ANALISAR: CRIAR UM SABER SOBRE A PULSÃO}

Ao escrever os textos de 1937, Freud estava às voltas com questões que se encontram no cerne da noção de construção do caso: como construir um saber sobre a verdade do sujeito que não surge sob a forma do retorno do recalcado? Como a verdade histórica é remanejada pelo saber?

Em Análise terminável e interminável, ao definir a expressão "término de uma análise”, estabelece as seguintes condições: 1) que o paciente não sofra mais de seus sintomas, ansiedades e inibições; 2) que o analista considere que a quantidade de material recalcado tornado consciente seja o suficiente para que o processo patológico não se repita (FREUD, 1937a/1996). Nota-se que o término da análise, nesta primeira definição, está ligado a uma tomada de posição do analista, pois depende de seu julgamento, o qual só pode ser efetuado a partir das hipóteses construídas para se pensar o caso e da avaliação da análise em questão. Isto é, a tomada de posição do analista tem relação direta com a construção que ele faz do caso.

Além disso, afirmar que o final de análise depende da quantidade de material recalcado tornado consciente é o mesmo que dizer que depende de uma aquisição de saber com o qual o sujeito consente. Isso remete ao que afirmamos no início do artigo: a produção do saber em psicanálise nunca se emancipou de sua terapêutica e sempre se fundou na investigação operada durante os processos analíticos.

Vale assinalar que o ganho de saber ocorre em diferentes registros. Por um lado, temos o saber produzido pelo próprio paciente em análise, que sofre, evidentemente, as incidências das interpretações do analista. Por outro, temos o saber produzido pelo próprio analista. Este último se desdobra no saber construído sobre a singularidade de um sujeito específico - e aqui estamos no âmbito da construção do caso - e no saber construído que permite certa generalização, podendo servir de baliza para a reflexão sobre outros casos - e aqui estamos no âmbito da teoria. 
Retornando à Análise terminável e interminável, é preciso dizer que Freud, no entanto, não se contenta com a primeira definição e propõe um segundo significado para a expressão "término de uma análise" que ele designa como ambicioso, pois supõe que uma influência tão poderosa da análise foi exercida sobre o paciente que se tornou impossível qualquer outra modificação no caso. A normalidade psíquica teria sido alcançada a partir da solução de todos os recalcamentos do paciente e do preenchimento de todas as lacunas em sua lembrança (FREUD, 1937a/1996). Neste ponto, Freud nos convida a examinar a experiência clínica e a teoria para descobrir se isso é possível. O resultado do duplo exame, como se sabe, é a série de obstáculos inventariados para que uma análise se cumpra de modo integral, o que o leva à conclusão da inexistência de uma análise sem restos.

A ideia de que no tratamento analítico existem sempre manifestações residuais é essencial no texto de Freud. Neste sentido ele se posiciona contra Rank, que defende que o recalque originário tenha um conteúdo determinado, sendo possível ir diretamente a este ponto. Para Freud, o recalque originário não tem conteúdo, o que faz com que a verdade de um sujeito não possa ser esgotada e que não exista uma última palavra em análise. A pergunta sustentada ao longo do texto é, justamente, a de saber como pensar a conclusão da análise sem essa última palavra. A saída freudiana é a de situar a conclusão da análise em dois pontos: na articulação do sujeito interpretável com a pulsão e no que ele denominou "estado criado" (FREUD, 1937a/1996, p.242).

Por um lado, Freud considera a possibilidade do "amansamento da pulsão" (FREUD, 1937a/1996, p.240-241), que não significa livrar-se dela, mas colocá-la em harmonia com o Eu, evitando que siga independentemente seu caminho para a satisfação. Sua posição, portanto, é a de que a psicanálise pode reconhecer o conflito entre o Eu e a pulsão, enfrentá-lo e transformá-lo, mas, em nenhum caso, pode eliminá-lo, o que faz com que a decisão do conflito pulsional, em psicanálise, se dê em função de um indecidível. Por outro lado, Freud aponta para certo efeito da análise: a elaboração de um "estado criado” do Eu, que não surge espontaneamente (FREUD, 1937a/1996). Esta é uma indicação importante, pois a expressão "estado criado" evoca a característica fundamental da análise, que se diferencia pela variedade dos tratamentos possíveis dados à pulsão a partir da abertura à surpresa, ao encontro e à invenção.

Em síntese, o que Freud acentua é que a análise envolve uma decisão — tanto do analista quanto do analisante - acerca de um indecidível relacionado à criação ou à invenção. Decisão esclarecida, evidentemente, que excede a determinação que o sujeito sofre do significante e do objeto que causa seu desejo, mas que, ao mesmo tempo, depende dela.

Quando mencionamos o indecidível no processo analítico, nos referimos, especificamente, ao que Freud situa no horizonte do final da análise, a saber, a 
incurável divisão do sujeito, o conflito entre a pulsão e o eu (ich). Diante disso, Freud não acredita que a análise venha a promover qualquer tipo de unificação ou totalização do psiquismo. Quando se pergunta como é que a análise pode intervir neste conflito, a resposta que lhe ocorre é dizer que ela pode reconhecê-lo e enfrentá-lo. Pode transformá-lo por meio de saídas e soluções criativas, mas, em nenhum caso, eliminá-lo.

Este aspecto da criação, retomado nos artigos Construções em análise e Moisés e o monotéísmo, é central quando pensamos na construção do caso, pois também aí está em jogo a construção de um saber sobre a pulsão, causa do sintoma do sujeito. Isso significa que a construção a respeito de um caso não se limita ao que se pode interpretar e decifrar do sintoma. Inclui igualmente a invenção de um saber sobre algo que não se encontra no registro das representações e que Freud, em 1937, chamou de “verdade”. Vejamos de que verdade se trata.

\section{CONSTRUÇÕES SOBRE A VERDADE HISTÓRICA}

Em Moisés e o monoteísmo, a edificação do judaísmo foi vista por Freud como um saber elaborado sobre a verdade histórica, que se refere, entre outras coisas, ao assassinato de Moisés por seu povo. Este assassinato é a causa ativa que permaneceu velada, na história da religião judaica. Freud, no entanto, num determinado momento, faz intervir uma causa e uma verdade mais arcaicas. Afirma que o assassinato de Moisés teria sido a repetição real do traço de memória esquecido do assassinato do pai da horda primitiva, e a ulterior reabilitação do Deus único pela religião judaica, a reconciliação com esse pai, determinada pelo sentimento de culpa (FREUD, 1939[1934-38]/1996).

Assim, para Freud, existem duas causas envolvidas na constituição da religião judaica, que ele faz equivaler ao sintoma: a primeira é o assassinato de Moisés, inscrição histórica, recalcada pelos relatos da tradição; a segunda não é da ordem do recalcado, pois não há inscrição histórica deste acontecimento. O assassinato do pai primitivo é um mito freudiano. Freud relaciona a primeira causa à verdade material (à materialidade dos fatos), e a segunda, à verdade histórica. Esta última tem relação com o fato de que, nos tempos primitivos, houve uma pessoa imensamente poderosa, que retornou posteriormente na memória dos homens, elevada à posição de divindade (FREUD, 1939[1934-38]/1996). Ou seja, a verdade histórica reporta-se à noção de nachträglich, explicitada na análise do caso Emma, no texto Projeto para uma psicologia científica (ano 1895). O caso ilustra o que Freud busca evidenciar com a definição de dois tipos de verdade que se articulam e atuam como causa do sintoma.

Como se sabe, Emma é uma moça que não é capaz de entrar sozinha numa loja e explica seu sintoma com a seguinte lembrança: aos 12 anos, entrou 
numa loja e, ao perceber o riso dos vendedores, assustou-se e fugiu (FREUD, 1950 [1895]/1996). Na análise, contudo, surge uma segunda lembrança. Aos oito anos, esteve em uma confeitaria e o confeiteiro tocara seus órgãos genitais. $\mathrm{Na}$ primeira cena, aos oito anos de idade, Emma não se abalou e, somente a partir da segunda, a primeira adquiriu valor traumático e desencadeou a angústia. $\mathrm{Na}$ opinião de Freud, a segunda situação (o riso dos vendedores) desperta um afeto que não pôde se expressar na primeira (a sedução do confeiteiro), e isso porque a puberdade tornou possível a Emma uma nova compreensão da primeira lembrança (idem). A nova compreensão surgida na puberdade preenche o vazio de significação da primeira cena de sedução.

A perspectiva freudiana é a mesma em Moisés e o monoté́smo: o sintoma da religião judaica é causado pela incidência de um fato posterior (o assassinato de Moisés) sobre um primeiro mais arcaico (o assassinato do pai da horda primitiva). Para Freud, a segunda situação - seja no caso Emma, seja no caso da religião judaica — remodela, posteriormente, aquilo que, na primeira situação, não conquistou representação no psiquismo.

Assim, pois, a visada de Freud oferece uma concepção do inconsciente antagônica à ideia de uma memória em que tudo já está dado e inscrito sob a forma do recalcado. O comentário acima deixa claro que o sintoma implica um manejo do saber no tempo, que faz surgir, do arcaico, algo que não podemos dizer que já estava aí.

É importante dizer que o saber elaborado pelo analisante, em análise, e pelo analista, na construção do caso, obedece ao mesmo modelo descrito. Trata-se de uma elaboração de saber que opera numa dupla vertente: na vertente das representações e da decifração do sentido do sintoma, mas também na da pulsão que não se inscreveu no psiquismo, que não pode ser rememorada, e que exige, portanto, uma criação, como Freud apontou em Análise terminável e interminável.

Essa perspectiva conduz Freud à noção de construção. A construção, em Moisés e o monoteísmo, são as roupagens míticas, históricas e sintomáticas edificadas em torno de um núcleo de verdade — o assassinato do pai e o de Moisés. Já em Construções em análise, são intervenções do analista que se distinguem da interpretação, na medida em que consistem em inventar algo onde o retorno do recalcado não se produziu.

\section{CRIAR/CONSTRUIR UM SABER SOBRE A VERDADE DO SUJEITO}

A construção aparece em Freud como um tipo de intervenção necessária ao desenvolvimento do trabalho analítico. O termo já havia sido utilizado por ele em Bate-se em uma criança, quando ele sustentou que o segundo tempo da fantasia nunca é lembrado pelo analisante e deve, portanto, ser construído 
em análise (FREUD, 1919/1996). Freud reconhece que há um ponto do inconsciente que não é linguagem e que não pode ser decifrado ou lembrado. Neste caso, a possibilidade de intervenção que se apresenta é a de se construir algo sobre o que não retorna no registro do significante. A construção se distingue da interpretação de sentido por não estar referida a uma significação inconsciente, e sim a uma dimensão do inconsciente que não se estrutura como uma linguagem.

Freud fornece critérios para diferenciarmos a construção da interpretação. A interpretação aplica-se a um elemento isolado, tal qual uma associação ou uma parapraxia, enquanto a construção apresenta ao paciente um fragmento de sua história primitiva (1937b/1996). Partindo deste ponto, Miller (1996) sugere que a construção é a estratégia pela qual o analista inventa uma coerência para os fragmentos de inconsciente que surgem isoladamente. O material inconsciente aparece aos pedaços e o analista, articulando esses pedaços, compõe um conjunto com a construção.

Todavia, a grande questão colocada por Freud, nesse texto, é a de saber que garantia tem o analista da correção de sua construção (1937b/1996). Ele se preocupa com o problema da garantia da verdade, ou seja, com a validade de seu método.

De início, Freud diz que não há problema se, ocasionalmente, cometemos algum equívoco e oferecemos ao paciente uma construção errada como sendo a verdade histórica provável. A construção falsa pode ser prontamente abandonada (idem). Essa posição indica que a construção não tem a ver com a exatidão do saber, mas com os efeitos provocados no sujeito pela comunicação desse saber. O que importa são os efeitos de verdade que a construção desse saber provoca e que podem ser reconhecidos nos elementos que aparecem de forma indireta. Assim, podemos concluir que, na construção, há de se fazer com que alguns significantes assumam o valor do fragmento do inconsciente que não retorna. A construção é uma metáfora na qual um saber substitui a verdade que não pode ser integralmente revelada. O problema é que não pode ser uma metáfora qualquer — deve ser uma metáfora prenhe de verdade.

Freud já havia abordado essa questão ao discutir o problema da profilaxia em psicanálise. Ele afirma que a tentativa de ativar, no paciente, conflitos pulsionais para tratá-los profilaticamente está fadada ao fracasso, pois o paciente escuta o que temos a dizer, mas não reage. Algo parecido ocorre quando um adulto fornece às crianças esclarecimentos sexuais. As crianças aprendem algo que não sabiam antes, mas não têm pressa em sacrificar as teorias que construíram em harmonia com sua organização libidinal infantil em prol deste novo conhecimento. Isso torna claro que o saber elaborado em análise, a partir da construção, deve ser equivalente àquele encontrado nas teorias sexuais infantis, as quais estão referidas 
à satisfação sexual do sujeito. O saber que vale, na análise, é aquele que enlaça o significante e o gozo para cada sujeito.

Resumamos então, o que este artigo traz como contribuição para nossa investigação. Em primeiro lugar, situa, mais uma vez, o trabalho analítico como um trabalho epistêmico no qual se encontra em questão a elaboração de um saber que convoca o consentimento do sujeito. Retoma também a ideia de que existe um ponto de indecidível no inconsciente que faz apelo à decisão e à criação. Trata-se da invenção de um saber que vem no lugar da verdade e que não pode ser qualquer um, pois deve produzir a convicção no paciente ao ser comunicado. A condição para que isso ocorra é que esteja referido ao gozo do sujeito em questão.

Examinados os três artigos freudianos de 1937, nosso próximo passo será o de verificar como os elementos ali apresentados podem servir-nos para fundamentar a construção do caso clínico em psicanálise.

\section{A VERACIDADE DA CONSTRUÇÃO DO CASO CLÍNICO}

Freud evidencia um aspecto fundamental quando interroga a garantia de correção da construção feita pelo analista. Vimos anteriormente que ele distingue exatidão e verdade.

Um exemplo clínico que demonstra isso com clareza é um fragmento da análise do Homem dos Ratos. Orientado pela hipótese do complexo de Édipo, Freud considera que o pai, nesse caso, apresentava-se como o agente perturbador do gozo sexual do paciente. Essa era a construção de Freud a respeito do caso e as interpretações que ele endereçava ao paciente privilegiavam a sobredeterminação significante do sintoma e a trama pulsional no mito edipiano (FREUD, 1909/1996).

Já nos primeiros encontros, ele diz ao paciente que, quando este tinha menos de seis anos, fora culpado de uma má conduta (masturbação), tendo sido duramente castigado pelo pai. A punição teria colocado fim à atividade masturbatória e produzido um rancor inextinguível do Homem dos Ratos em relação ao pai (idem).

Para surpresa de Freud, essa comunicação provoca como resposta o relato de uma cena que a mãe do paciente lhe havia narrado. É de se notar que, de acordo com o Homem dos Ratos, ele mesmo não se recordava do evento e que, portanto, a intervenção de Freud não teria provocado o levantamento da amnésia ou do recalque. A cena relatada havia acontecido quando ele, com três ou quatro anos de idade, cometera uma travessura. O pai batera nele e, tomado de uma ira terrível, a criança respondera com uma série de insultos. Esta experiência provocou uma mudança no caráter do menino, pois, a partir daquele momento, 
tornou-se, segundo suas palavras, "um covarde", por medo da violência de sua própria raiva (idem).

Depois de ter feito o relato na análise, o paciente conversou com a mãe a respeito do episódio e esta confirmou sua ocorrência, acrescentando que a punição que o pai lhe havia infligido deveu-se ao fato de ele ter mordido a babá. Ora, para Freud, não havia dúvidas de que a ação cometida pelo menino fora de natureza sexual. O importante, no entanto, é que a partir daí, segundo Freud, cedeu a recusa do paciente em acreditar na raiva adquirida contra seu pai (idem).

Este fragmento de análise evidencia o papel da construção do caso na orientação das intervenções do analista. A cena à qual a construção de Freud conduz, embora não tenha sido rememorada pelo paciente, aparece como indicativa de uma satisfação pulsional não conhecida e permite ao sujeito circunscrever um ponto do Real para extrair dali a convicção acerca da construção que lhe fora comunicada. O fragmento também mostra que o que indica ao analista a veracidade ou não de sua construção sobre o caso são os elementos surgidos no processo analítico, que podem confirmá-la ou refutá-la.

\section{A CONSTRUÇÃO DO CASO E O MANEJO DA VERDADE POR UM SABER QUE NÃO SE COMPLETA}

Outro ponto importante, apontado por Freud, diz respeito ao ganho de saber que a análise propicia. No processo clínico/investigativo da análise, de um lado, o paciente elabora um saber sobre seu sintoma e sobre a verdade de seu desejo; de outro, o analista constrói um saber sobre o caso clínico. Em ambos os casos há um manejo do saber que permite revelar algo da verdade do sujeito.

A ideia de Freud é a de que não existe análise integral, sendo o resto inanalisável, que se depura do processo analítico, a angústia de castração. Já para Lacan, é o objeto pequeno a que se subtrai a toda operação de decifração.

É importante dizer que a dimensão da incompletude no saber produzido em análise pode ser igualmente reconhecida no saber elaborado pelo analista na construção do caso e deve ser preservada.

Quando construímos um saber sobre um caso, preservamos um ponto de vazio que impede que a verdade sobre o paciente seja totalizada. A manutenção deste vazio é o que permite que as construções sobre o caso possam ser sempre reconstruídas, e novas soluções formuladas. Na construção do caso, portanto, o analista também está aberto à surpresa e à invenção. Isto significa que os elementos contingentes surgidos no tratamento analítico interferem constantemente na construção do saber sobre o caso. Por outro lado, como veremos no próximo seguimento, a construção do caso clínico é um processo no qual se depura, do saber, o resto mencionado acima. 


\section{A CONSTRUÇÃO DO CASO E A POLÍTICA DO ANALISTA}

Em primeiro lugar, ressaltemos o fato de que o analista é responsável pelo tratamento, como assinala Freud ao dizer que os acontecimentos na análise dependem de sua decisão e julgamento. Para Lacan (1958/1998), o analista não dirige o paciente, mas sim o tratamento, e, para fazê-lo, é necessário algum tipo de orientação. Para explicitar de que orientação se trata, Lacan, inspirado na sistematização de Clausewits, propõe que as ações do analista devem se organizar em três níveis: o da tática, o da estratégia e o da política. Ele situa a interpretação no nível da tática, o manejo da transferência no nível da estratégia e a falta-a-ser no nível da política, afirmando que, no final, a política é o que decide uma guerra.

De acordo com Lacan, a política da psicanálise se orienta pela falta-a-ser, que se encontra no coração da experiência analítica. A expressão falta-a-ser, relativa ao desejo, só ganha sentido quando consideramos que o sujeito foi separado de seu ser, em função da castração. E o mais importante é que Lacan coloca, em determinado momento, o objeto no lugar do ser perdido pelo sujeito, o que pode ser constatado na proposição de que o objeto toma o lugar daquilo que o sujeito foi privado simbolicamente (1959/1981).

Ou seja, dizer que a política do analista é orientada pela falta-a-ser é o mesmo que dizer que ela é orientada pelo objeto pequeno a, causa do sintoma e do desejo. A política do analista, neste sentido, visa circunscrever e depurar, do sintoma, este objeto que tem o estatuto de Real. É esse manejo que orienta fundamentalmente as ações do analista no tratamento.

A política do analista se define a partir da construção do caso, que consiste em inventar uma coerência para fragmentos do inconsciente que aparecem desarticulados durante o processo analítico e que possibilita não apenas uma visão geral do tratamento, mas também a elaboração de hipóteses que orientarão as intervenções clínicas. A construção permite ao analista localizar o seu lugar na transferência em função do qual lançará suas interpretações. Permite, ainda, o manejo da transferência ao se reconhecer o objeto pequeno a que o sintoma singular do sujeito circunscreve.

Tendo sido localizados os fundamentos teóricos da noção de construção de caso clínico, buscaremos definir, em seguida, alguns passos desta metodologia, tomando como referência as elaborações de Viganò.

\section{A CONSTRUÇÃO DO CASO E O TEMPO}

O psicanalista italiano trabalha a construção do caso a partir da estrutura do tempo lógico proposta por Lacan no texto O tempo lógico e a asserção da certeza antecipada: o instante de ver, o tempo de compreender e o momento de concluir que antecedem a afirmação do prisioneiro a respeito da cor do disco pregado em 
suas costas (1945/1998). A construção equivaleria ao tempo de compreender, que deve preceder o ato analítico e que corresponde ao ato do prisioneiro de se dirigir ao diretor da prisão para informar-lhe sua conclusão. No processo temporal, os componentes recolhidos da fala e dos atos do sujeito permitem ao analista reconhecer sua posição no discurso, estabelecer um diagnóstico estrutural e localizar o gozo singular que seu sintoma circunscreve. É a partir deste ponto singular que é possível para o analista lançar seu ato, sobre o qual somente o paciente poderá testemunhar (VIGANÒ, 1999).

Tanto na construção do caso quanto no apólogo dos três prisioneiros não se tem um acesso direto à verdade, a qual é alcançada em função da elaboração de um saber. No caso do apólogo, o modo como o diretor dispõe os círculos nas costas de cada um dos prisioneiros faz com que, num primeiro momento, o problema pareça insolúvel. Cada prisioneiro, vendo dois círculos brancos e sabendo que existem três círculos brancos e dois pretos, não pode deduzir nada.

Do ponto de vista da lógica clássica, diante da impossibilidade de se resolver algo com a visão de dois discos brancos, seria necessário renunciar a qualquer conclusão, na medida em que ela só considera a concepção espacializada do processo lógico: o que pode ser visto logo de início (LACAN, 1945/1998).

A genialidade de Lacan é a de incluir dados complementares na resolução do problema. Os dados iniciais são o número de prisioneiros e de discos, que todos conhecem. Os dados complementares são o tempo e o direito de pensar, mais além dos dados iniciais, que fazem prevalecer a estrutura temporal do processo lógico (idem).

Foi a partir da exclusão desta dedução simples que Lacan introduziu a modulação do tempo, fazendo prevalecer a estrutura temporal, e não a estrutura espacial do processo lógico. É a exclusão dos dois discos pretos, que não são vistos por nenhum dos prisioneiros, que faz esses discos entrarem, no processo, como significantes - como presença correlativa a uma ausência.

Nosso intuito é evidenciar que, no apólogo, o que se inscreve como saber depende de um não saber. Depende da marca da ausência dos dois discos negros, impressa no processo lógico. Temos pelo menos duas ideias fundamentais em jogo no texto. A primeira é que a verdade deve ser apreendida, pois não temos acesso direto a ela. A segunda é que essa verdade é apreendida de modo antecipado. Tanto o prisioneiro quanto o analista decidem sobre a verdade sem conhecê-la inteiramente. Verdade que será submetida à prova, mas que não seria verificada se eles não a atingissem na certeza.

Para Viganó (2010a), o ato analítico é o resultado do processo da construção do caso, no qual um saber é elaborado sobre o objeto causa de desejo do analisante, precipitando um ato conclusivo. No processo analítico, o objeto causa de desejo equivale ao disco que o prisioneiro porta nas costas sem conhecê-lo. 
A conclusão, na análise, surge como escansão no tempo de compreender, que lhe antecede. Põe um termo no tempo de elaboração. A conclusão é solidária com o ato do analista, pensado como decisão e aposta, e que, mais tarde, será verificado.

\section{A ESCRITA, A SUPERVISÃO, E A REDUÇÃO DO CASO COMO MÉTODO}

A validade do método proposto por Viganó depende da passagem dos elementos discursivos de um dado sujeito por quatro tempos, tendo como princípios a escrita e a interlocução do clínico com um supervisor e com os diversos membros da equipe interdisciplinar (VIGANÒ, 2010a).

Os elementos a serem incluídos na escrita do caso são escolhidos com base nas recomendações de Freud aos médicos que exercem a psicanálise. O psicanalista afirma que os relatórios exatos de histórias clínicas são de pouco valor e possuem apenas "a exatidão ostensiva de que a psiquiatria moderna fornece-nos alguns exemplos marcantes" (FREUD, 1912/1996, p.127). Propõe que o material obtido a partir das falas do paciente forma um texto coerente que poderá ser posteriormente anotado, de memória, por ele. Assim, pois, pode-se dizer que os elementos que compõem a escrita do caso, em processo de construção, são depurados por meio da escuta flutuante do analista, durante os atendimentos, e sem a tomada de notas integrais.

No método da Construção, a ideia é fazer com que o caso sofra uma redução até o ponto em que se toca o impossível de ser dito, o objeto a que não se traduz pelo significante. Este processo se aproxima do que Miller chamou de “operação-redução”, no comentário que ele tece sobre o trabalho analítico em O osso de uma análise (MILLER, 1998).

Miller observa que quando solicitamos ao analisante que associe livremente, o que ocorre é que, apesar da liberdade para falar, certos temas e palavras reaparecem de forma recorrente, o que permite a localização de alguns enunciados fundamentais. Frases ou palavras pronunciadas pelos pais ou por outros, que adquiriram valor especial na vida daquela pessoa. São os lugares fixos do inconsciente que se desenham no desenrolar da análise e que podem ser descritos como funções proposicionais $\mathrm{f}(\mathrm{x})$, nas quais diversos termos se sucedem como variáveis da mesma propriedade f (MILLER, 1998).

Estes pontos fixos do inconsciente são significantes destacados à força da repetição. Miller, ao discutir a repetição significante, evoca o modelo de Lacan apresentado no posfácio do Seminário sobre a "Carta roubada". Este modelo, como se sabe, é construído a partir de jogadas com uma moeda não viciada. Assinala-se (+) quando sai cara e (-) quando sai coroa. A partir destes sinais, codificam-se os pares de jogadas e obtém-se uma sintaxe que determina uma escrita, diferente do início em que podíamos obter aleatoriamente $(+)$ ou $(-)$. Desta forma, 
Lacan mostra que o aparecimento de alguns termos na cadeia exige a presença consecutiva de certos termos e proíbe a presença de outros. Ou seja, a sintaxe que exige determinada escrita proíbe, ao mesmo tempo, outra (idem).

O que encontramos na situação que acabamos de mencionar é justo a emergência de um necessário e, consequentemente, de um impossível, a partir do acaso. Miller usa esse modelo para demonstrar que o avesso da repetição significante necessária é um impossível de se escrever. O que se repete, como escrita necessária do inconsciente, convoca, ao mesmo tempo, outro tipo de repetição, que tem a ver com a evitação. Ou seja, quando determinados termos são "escolhidos" para se apresentarem na cadeia, isso significa que outros termos são recusados.

E se nos perguntamos por que tal significante se escreveu no inconsciente de alguém ou por que adquiriu valor em sua economia psíquica, não podemos mais responder com o registro do necessário e do impossível. Temos que passar à contingência. Entre o significante que determina o sujeito e o investimento libidinal, com o qual ele é dotado, há um hiato, uma ruptura de causalidade. Isto faz parte do caráter acidental que envolve a vida das pessoas. Uma frase escutada aqui, uma cena assistida acolá, e pronto: vemos nosso sujeito às voltas, pelo resto da existência, com seus oráculos particulares, sem que conheçamos a razão do investimento libidinal destas palavras.

Isso mostra que, se por um lado, o sujeito é calculável em função das operações metafóricas e metonímicas da linguagem, o investimento pulsional não o é. Aqui temos outra ordem de fatos que se reporta à contingência da intrusão do gozo no ser humano.

No processo de construção do caso articulam-se o necessário da repetição da cadeia significante, o impossível de ser rememorado pela cadeia e a contingência do investimento libidinal, que explica a impossibilidade da verdade ser dita toda na experiência analítica. Busca-se reduzir o caso clínico aos significantes fundamentais e necessários do sujeito, supondo que essa redução demarcará, ao mesmo tempo, um impossível e a contingência/singularidade da instituição de certo modo de gozo para um sujeito. Nos limites do texto extraído da operação-redução realizada no processo de construção do caso, circunscrevemos o Real que se apresenta, justamente, como impasse da escrita.

Uma vez estabelecida a ideia de que a construção do caso é consequência de um trabalho de redução efetuado sobre o discurso do paciente, buscaremos, agora, localizar quatro momentos possíveis e não necessários deste processo. ${ }^{1}$ Ressaltamos, mais uma vez, que não temos a intenção de propor, aqui, uma

\footnotetext{
${ }^{1}$ Os momentos da metodologia foram elaborados a partir de uma supervisão com o psicanalista Carlo Viganó realizada em Milão, em 2009, e de importantes contribuições de outros pesquisadores sobre o tema - em especial Roberto Assis Ferreira, Daniela Costa Bursztyn e Jeferson Machado Pinto.
} 
metodologia própria à psicanálise, e, sim, de estabelecer algumas orientações para a construção do caso. A definição destes quatro momentos serve apenas aos fins de transmissão. Evidentemente, este percurso pode ocorrer de maneira diferente, ser feito mais de uma vez durante a condução de um tratamento, ou não se reduzir aos quatro tempos.

\section{Relato da história}

O processo tem início quando o analista elege o caso e faz uma compilação, de memória, dos conteúdos das sessões em um texto com o formato de história clínica. Esta história é fundamental, pois a partir dela pode ser gerada a possibilidade de se iniciar a construção do caso. A própria eleição do caso já modifica o olhar que o analista tem sobre o paciente. Este texto inicial traz uma visão geral do caso, de onde é possível extrair uma questão específica de acordo com o estilo e interesse particular do analista.

\section{Supervisão}

A partir da supervisão individual com outro analista, esta questão torna-se mais circunscrita e os elementos singulares do caso tomam contornos mais nítidos. Neste momento, os significantes fundamentais do sujeito que se destacaram à força da repetição ganham maior relevo.

A supervisão possibilita ao analista localizar os pontos em que a relação com sua fantasia produz obstáculos para a extração da lógica do caso e, por conseguinte, permite-lhe reorientar sua posição na transferência. É o lugar privilegiado para que a prática do analista na instituição e em equipe interdisciplinar passe pelo crivo da psicanálise pura. O ato do analista, neste âmbito, é retomado, comentado e verificado, com o intuito de discernir, por meio dos significantes, o Real aí implicado.

O saber gerado por esse comentário não tem relação com o acúmulo de conhecimento, e sim com a apreensão de um "saber fazer" com o caso clínico. O que se produz na supervisão permite um novo recorte do caso e, então, mais um texto é produzido, agora ainda mais reduzido. Este texto funcionará como eixo condutor para a discussão da equipe na medida em que localiza um impasse na condução do caso.

\section{Reunião da equipe}

$\mathrm{Na}$ equipe, os elementos do texto podem ser verificados e ampliados a partir da conversação com outros profissionais envolvidos no caso, os quais assumem uma posição de ignorância em função do privilégio conferido à pesquisa e ao questionamento, próprios da clínica. Neste momento, segundo Viganó (2003), 
é importante a adesão de cada um da equipe a partir do que há de mais vivo em seu desejo, tornando-os responsáveis frente ao trabalho clínico.

Nesta conversação, é fundamental a presença de "pelo menos um" que suporte o lugar do não saber e que poderá ser alguém exterior à equipe, responsável pelo balizamento da discussão. O ponto de não saber permite que a verdade sobre o paciente não seja jamais totalizada e que as construções sobre o caso possam ser sempre renovadas e repensadas. Possibilita também a invenção de novos saberes e soluções, pois leva em conta as contingências, as idiossincrasias e as singularidades encontradas na experiência clínica como pontos de variação da estrutura teórica já constituída.

O singular do caso, que Viganó chama de Real, não é dedutível de um saber universal, já dado, mas deve ser extraído pelo processo de redução do caso aos seus significantes mínimos, como foi descrito anteriormente. É a partir deste ponto que se pensa nas estratégias e intervenções possíveis que visam o reposicionamento do sujeito frente a seu sintoma.

\section{Aprendendo com o paciente}

No quarto momento ocorre a verificação do que se construiu do caso a partir da resposta do paciente às intervenções da equipe. Afinal, apesar da construção do caso incluir elementos discursivos de vários protagonistas envolvidos, o referencial é sempre o sujeito, e suas produções funcionam como o pivô na direção de seu tratamento.

É importante assinalar, no entanto, que nos referimos, aqui, a um tipo específico de resposta. Freud afirma que o que conta é a elaboração, por parte do analisante, de novas associações (1937b/1996). O que confirma ou refuta a construção do analista é a resposta do inconsciente, que vem à tona de forma indireta, como as recordações vivas de detalhes relativos a um determinado acontecimento, tanto em sonhos quanto em fantasias (idem).

Por isso, Viganó (2010b) ressalta que aquilo que o paciente ensina a respeito da construção de seu caso não passa por sua consciência nem pela fala direta, mas sim pela escuta que o analista faz das particularidades e das coincidências, escandidas de sua história, e também do enigma de seus atos falhos, recaídas e ausências. Podemos dizer, portanto, que a construção do caso atua après coup — “após o golpe" — ou seja, continua após o ato analítico, quando o verifica, evidencia-o e o avalia. Neste tempo, é possível a construção de um último texto, no qual a conexão entre o que se apreendeu do caso e o tratamento possível pode ser transmitida. 


\title{
REFERÊNCIĀS
}

FREUD, S. (1996) Edição standard brasileira das obras psicológicas completas de Sigmund Freud. Rio de Janeiro: Imago.

(1909) "Notas sobre um caso de neurose obsessiva”, v.X, p.139-215.

(1912) "Recomendações aos médicos que exercem a psicanálise", v.XII, p.125-133.

(1913 [1911]) “Sobre a psicanálise”, v.XII, p.225-229.

(1913) "Sobre o início do tratamento (Novas recomendações sobre a técnica da psicanálise I)”, v.XII, p.139-158.

(1919) "Bate-se em uma criança”, v.XVII, p.195-218.

(1923 [1922]) "Dois verbetes de enciclopédia”, v.XVIII, p.253-274.

(1937a) “Análise terminável e interminável”, v.XXIII, p.231-270.

(1937b) “Construções em análise”, v.XXIII, p.275-287.

(1939 [1934-38]) “Moisés e o monoteísmo”, v.XXIII, p.19-149.

(1950 [1895]) “Projeto para uma psicologia científica”, v.I, p.347-443.

FIGUEIREDO, A. C. (2004) A construção do caso clínico: uma contribuição da psicanálise à psicopatologia e à saúde mental. Rev. latinoam. psicopatol. fundam., 7(1). São Paulo: Associação Universitária de Pesquisa em Psicopatologia Fundamental, p.75-86.

LACAN, J. (1998) Escritos. Rio de Janeiro: Jorge Zahar.

(1945/1998) "O tempo lógico e a asserção da certeza antecipada", p.197-213.

(1948/1998) “A direção do tratamento e os princípios de seu poder”, p.591-652.

(1959/1981) Le désir et son interprétation — Hamlet (Séances

du 4 et 11 mars 1959). Ornicar?, n.26-27. Paris: Navarin, p.7-34.

(1972-73/1975) Seminário XX. Rio de Janeiro: Jorge Zahar.

MILlER, J. A. (1996) A marginália de construções em análise. Opção Lacaniana, n.17. São Paulo: Edições Eólia, p.92-107. (1998) O osso de uma análise. Salvador: EBP.

VIGANÒ, C. (1999) A construção do caso clínico em saúde mental. Curinga, v.13. Belo Horizonte: EBP-MG, p.50-59.

. (2003) A construção do caso. Almanaque de Psicanálise e Saúde Mental, 6(9). Belo Horizonte: IPSMMG, p.47-53.

(2010a) Avaliação e evidência em saúde mental. Rev. latinoam. psicopatol. fundam., 13(3). São Paulo: Associação Universitária de Pesquisa em Psicopatologia Fundamental, p.469-481.

(2010b) A construção do caso clínico. Opção Lacaniana on line, ano I, março de 2010. Disponível em: www.opcaolacaniana.com.br. Acesso em: 1/4/2010.

\author{
Alexandre Costa Val \\ alecostaval@yahoo.com.br \\ Mônica Assunção Costa Lima \\ lmonica.lima@gmail.com
}

